\title{
Recurrent Liver Abscess from Klebsiella pneumonia
}

\author{
Waleed Tariq Siddiqui ${ }^{1 *}$ and Howard Quentzel ${ }^{2}$ \\ ${ }^{1}$ Department of Internal Medicine, Griffin Hospital, USA \\ ${ }^{2}$ Department of Infectious Diseases, Griffin Hospital, USA \\ *Corresponding author: Waleed Tariq Siddiqui, Department of Internal Medicine, Griffin Hospital, USA
}

\begin{tabular}{|c|c|}
\hline ARTICLE INFO & ABSTRACT \\
\hline Received: 豐 June 11, 2020 & Pyogenic liver abscess caused by Klebsiella pneumoniae is an emerging disease. \\
\hline Published: 幽 June 23, 2020 & $\begin{array}{l}\text { Diabetes mellitus appears to be a strong predisposing factor for this disease. Recurrent } \\
\text { liver abscess by Klebsiella is rarely reported in literature. Here we present a case of a } 52\end{array}$ \\
\hline $\begin{array}{l}\text { Citation: Waleed Tariq Siddiqui, Howard } \\
\text { Quentzel. Recurrent Liver Abscess from } \\
\text { Klebsiella pneumonia. Biomed J Sci \& Tech } \\
\text { Res 28(3)-2020. BJSTR. MS.ID.004654. }\end{array}$ & $\begin{array}{l}\text { abdominal pain. He was found to have } 4 \mathrm{~cm} \text { hypoattenuating lesion on his CT abdomen. } \\
\text { Aspiration of the lesion confirmed diagnosis of liver abscess by Klebsiella pneumoniae. } \\
\text { His initial episode was } 10 \text { years ago. It did not appear that this process was related } \\
\text { to the one } 10 \text { years ago as he had intervening CT scans of his abdomen which were } \\
\text { negative. Aspiration with drainage and prolonged course of IV antibiotics for } 4-6 \text { weeks } \\
\text { remains to be the treatment of choice. }\end{array}$ \\
\hline
\end{tabular}

\section{Introduction}

Pyogenic Liver Abscess (PLA) is a potentially lifethreatening condition with a significant mortality up to $19 \%$ [1]. The most commonly associated bacteria are Escherichia coli, Enterobacteriaceae, anaerobes, and other members of the gastrointestinal tract. However, in the past 2 decades over $50 \%$ to $88 \%$ cases of PLA in the Asian population have been reported due to Klebsiella pneumonia. It has also emerged with increasing frequency in South Africa, Europe, and the United States [2]. Recurrent Klebsiella pneumonia liver abscess are rarely reported in literature. Here we describe a case of a pyogenic liver abscess caused by Klebsiella pneumonia with recurrence after 10 years.

\section{Case Description}

52-year-old Hispanic male presented to the emergency department with complaints of fevers, chills and abdominal pain for the past week. His medical history was significant for hypertension, poorly controlled diabetes and a liver abscess secondary to Klebsiella 10 years ago. He had no nausea or vomiting and didn't feel that the pain had any relationship to food. His bowel habits were unchanged without diarrhea, constipation, melena, or bright red blood per rectum. He had been taking over the counter antacid for the pain which provided mild relief. He denied any history of travel outside of the United States. He felt that the pain was similar to when he was diagnosed with a liver abscess a decade ago (Figure 1). He was told at that time that the liver abscess potentially came from his job being in close contact with raw sewage however, he no longer did this now and was unemployed. On evaluation in the emergency department, he was febrile to $103 \mathrm{~F}$ and tachycardic to 110. Initial laboratory data revealed a white blood cell count of 9000 with $88 \%$ granulocytes, 9.9\% lymphocytes, hemoglobin 13.7, platelets 311 , glucose 333, BUN/creatinine 14 and 0.6, lactic acid 3.6. His liver function tests showed total bilirubin 0.9, direct bilirubin 0.5, AST 24, ALT 26 and alkaline phosphatase 150. A CT of the abdomen and pelvis with contrast revealed a $4 \mathrm{~cm}$ hypoattenuating mass in the liver (Figure 2). His clinical presentation and imaging findings were consistent with a recurrent liver abscess. This was his second episode of pyogenic liver abscess by Klebsiella pneumoniae. His first episode was in May of 2008 and the current one in April of 2018. His blood cultures drawn on admission remained negative. He was initially started on IV Ceftriaxone and Metronidazole. He underwent a CT guided drainage of abscess with cultures significant for Klebsiella Pneumoniae (sensitivity profile Figure 3). His antibiotics was switched to IV Ampicillin/Sulbactam. Interestingly, the culture and sensitivity profile of the organism was identical to the abscess 10 years ago (Figure 4). He was treated with 4 week course of IV Ampicillin/Sulbactam with complete resolution of symptoms. 


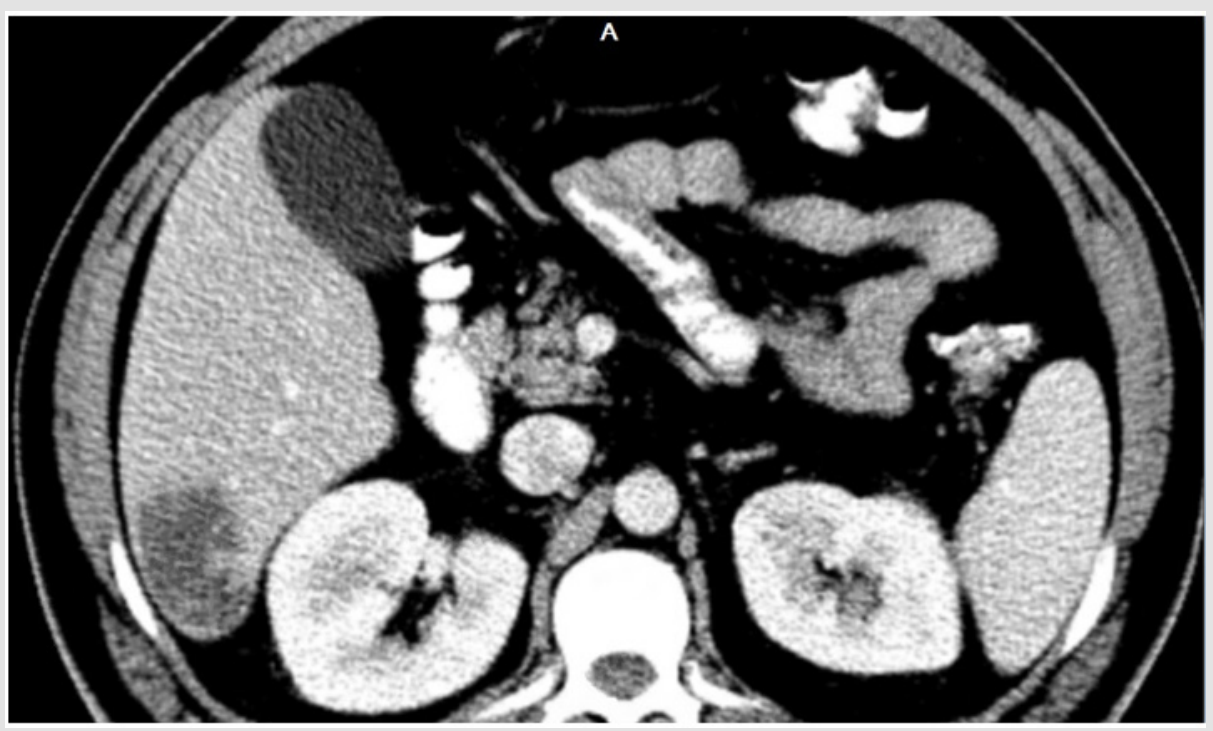

Figure 1.

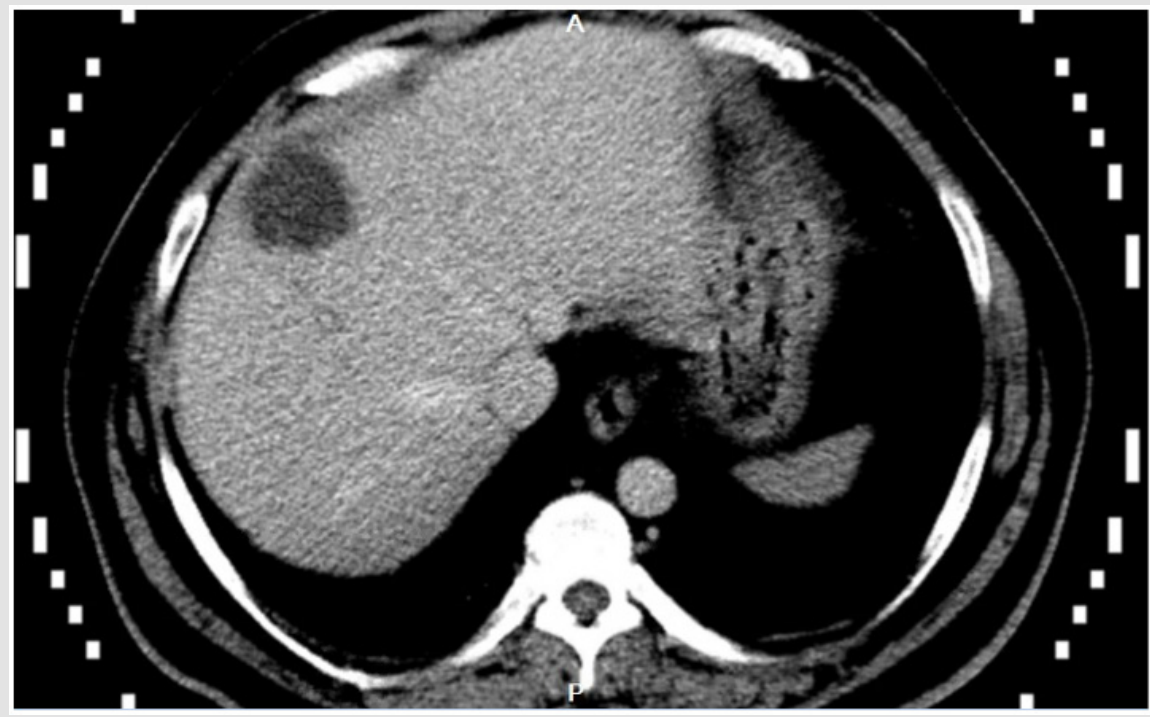

Figure 2.

\section{KLEBSIELLA PNEUMONIAE}

$\begin{array}{ll}\text { AMPICILLIN } & \text { R } \\ \text { CEFAZOLIN } & \mathrm{S} \\ \text { AMOXICILIIN/CLAVULINIC ACID } & \mathrm{S} \\ \text { AMPICILLIN/SULBACTAM } & \mathrm{S} \\ \text { CIPROFLOXACIN } & \mathrm{S} \\ \text { GENTAMICIN } & \mathrm{S} \\ \text { TRIMETHOPRIM/SULFAMETHOXAZOLE } & \mathrm{S}\end{array}$

Figure 3. 


\section{KLEBSIELLA PHEIMMONIAE}

\begin{tabular}{|c|c|}
\hline & $\underline{\mathrm{RX}}$ \\
\hline AMPIC ILL IN & $\mathrm{R}$ \\
\hline CEFAZOL IN & 5 \\
\hline AMOXICILLIM/CLAUILLINIC ACID & 5 \\
\hline AMP IC ILL IN/SIJLBAC TAM & 5 \\
\hline GENTAMICIN & 5 \\
\hline TR IME THOPR IM/SIILFAME THOXAZOLE & 5 \\
\hline
\end{tabular}

Figure 4.

\section{Discussion}

Pyogenic liver abscess occurs when the immune system fails to clear the infection in the liver parenchyma. There are multiple sources that are presumed to contribute in the pathogenesis of the disease. Infection can arise either from the biliary tree, portal vein, hepatic artery or directly from a contiguous source [3]. Most PLA are cryptogenic (primary) origin or arise from the biliary tree [4]. A stricture from underlying gallstones or malignancy and surgical manipulation of the biliary tract can predispose to infection of the biliary system [5]. Inflammation of the gastrointestinal tract either from appendicitis, diverticulitis, colorectal carcinoma and inflammatory bowel disease can spread infection via the portal venous system. Bacteremia from Staphylococcus aureus, can lead to secondary liver abscess via the hepatic artery [6]. Pyogenic liver abscess due to Klebsiella pneumoniae is an emerging disease. In the United States, one report documented that $41 \%$ of cases were caused by K. pneumoniae. Furthermore, this pathogen was isolated only from patients of Asian and Hispanic descent [7]. Interestingly, liver abscess by K. pneumoniae rarely have the typical biliary or portal venous route of infection [8]. Our patient had extensive abdominal imaging including ultrasound, MRCP and CT scan which did not reveal any evidence of biliary or pancreatic disease, malignant stricture or inflammation of the GI tract. It also did not appear that this process was related to the one 10 years ago as he had intervening CT scans of his abdomen which were negative Diabetes mellitus appears to be a strong risk factor for pyogenic liver abscess caused by Klebsiella pneumonia [9]. In May of 2008 when the patient had initially presented his HbA1c was 8.5. When he was admitted in April of 2018, his HbA1c was 11.2. Diabetics are believed to have a significant impairment in their immune system. The diminished function of polymorphonuclear leukocytes, impaired adherence, chemotaxis and phagocytosis are all believed to play a role. There is also some data to suggest that improving glycemic control in patients improves immune function [10]. In a case series of 6 patients by Yang YS et al, it was found that 4 of the 6 patients had poor glycemic control with $\mathrm{HbA1c}>9.0$. The average duration between the first episode and recurrence was 7.6 years with a range of 2 to 20 years [7].
Patients with $\mathrm{K}$ pneumoniae liver abscesses typically present with fever, chills, and abdominal pain [11]. The diagnosis of pyogenic liver abscess is often established using abdominal imaging. Abdominal CT is recommended for diagnosis as it offers better sensitivity than ultrasonography [100\% vs $85.8 \%$ ] [12]. Factors that favor Klebsiella liver abscess on CT scan include single abscess, unilobar (commonly right) involvement, and solid or multiloculated appearance. Most abscesses are often confined to the right hepatic lobe likely due to its rich blood supply from the portal vein, dense hepatic tissue and network of bile canaliculi [13]. The most effective treatment of Klebsiella liver abscess includes antibiotic therapy for 4-6 weeks combined with percutaneous drainage [14]. In conclusion, given the emerging nature of this disease especially in the poorly controlled diabetic population, clinicians should maintain a high degree of suspicion even in the absence of positive blood cultures. Early diagnosis and treatment can lead to a favorable outcome.

\section{References}

1. Du ZQ Zhang LN, Lu Q Ren YF, Lv Y, et al. (2016) Clinical Charateristics and Outcome of Pyogenic Liver Abscess with Different Size: 15-Year Experience from a Single Center. Sci Rep 6:35890.

2. Serraino C, Elia C, Bracco C, Rinaldi G, Pomero F, et al. (2018) Characteristics and management of pyogenic liver abscess: A European experience. Medicine (Baltimore) 97(19): e0628.

3. Mavilia MG, Molina M, Wu GY (2016) The evolving nature of hepatic abscess: a review. J Clin Transl Hepatol 4: 158-168.

4. Hansen PS, Schonheyder HC (1998) Pyogenic hepatic abscess. A 10-year population-based retrospective study. APMIS 106: 396-402.

5. Peng YC, Lin CL, Sung FC (2018) Risk of pyogenic liver abscess and endoscopic sphincterotomy: A population-based cohort study. BMJ Open 8(3): e018818.

6. Sifri CD, Madoff LC (2015) Infections of the Liver and Biliary System (Liver Abscess, Cholangitis, Cholecystitis). In: Bennett JE, Dolin R, Blaser MJ, (eds.), Mandell, Douglas, and Bennett's Principles and Practice of Infectious Diseases. 8th ed. Philadelphia: Elsevier Saunders; pp. 960

7. Yang YS, Siu LK, Yeh KM, Fung CP, Huang SJ, et al. (2009) Recurrent Klebsiella pneumoniae liver abscess: clinical and microbiological characteristics. J Clin Microbiol 47(10): 3336-3339.

8. Kim JK, Chung DR, Wie SH, Yoo JH, Park SW (2009) Korean Study groupfor Liver abscess. Risk factor analysis of invasive liver abscesscaused by the K1 serotipe Klebsiella pneumoniae. Eur J ClinMicrobiol Infect Dis 28: 109-111.

9. Kornum JB, Thomsen RW, Riis A, Lervang HH, Schonheyder HC, et al. (2008) Diabetes, glycemic control, and risk of hospitalization with pneumonia: a population-based case-control study. Diabetes Care 31: 1541-1545.

10. Jun JB (2018) Klebsiella pneumoniae Liver Abscess. Infect Chemother 50(3): 210-218.

11. Lin AC, Yeh DY, Hsu YH, Wu CC, Chang H, et al. (2009) Diagnosis of pyogenic liver abscess by abdominal ultrasonography in the emergency department. Emerg Med J 26: 273-275.

12. Alsaif HS, Venkatesh SK, Chan DS, Archuleta S (2011) CT appearance of pyogenic liver abscesses caused by Klebsiella pneumoniae. Radiology 260(1): 129-138. 
13. Ruiz-Hernández JJ, León-Mazorra M, Conde-Martel A, Marchena-Gómez J, Hemmersbach-Miller M, et al. (2007) Pyogenic liver abscesses: mortality-related factors. Eur J Gastroenterol Hepatol 19(10): 853-858.
14. Cosme A, Ojeda E, Zamarrẽno I, Bujanda L, Garmendia G, et al. (2010) Abscess hepatic pyogenic versus amebic. Comparative clinical study of a series of 58 cases. Rev Esp Enferm Dig. 102: 2.
ISSN: $2574-1241$

DOI: $10.26717 /$ BJSTR.2020.28.004654

Waleed Tariq Siddiqui. Biomed J Sci \& Tech Res

(C) (i) This work is licensed under Creative

Submission Link: https://biomedres.us/submit-manuscript.php

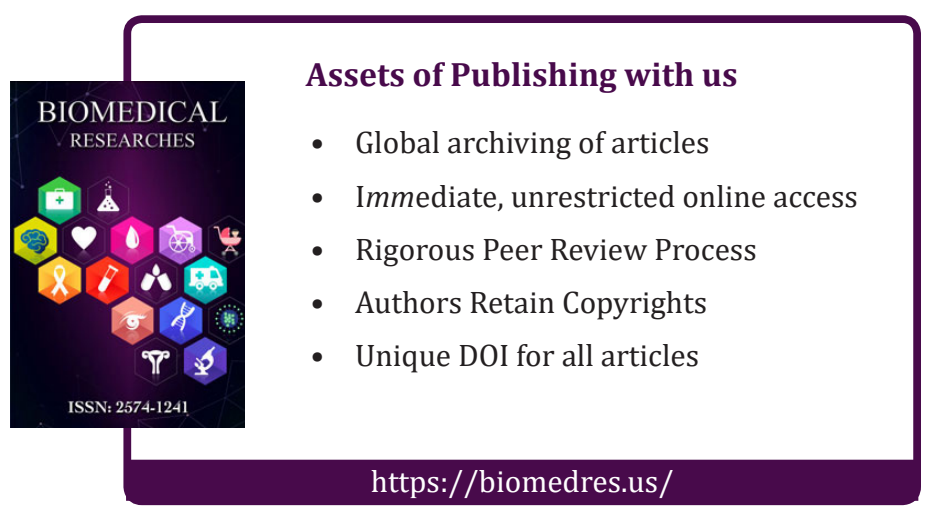

